\title{
JUEGO E IMAGINACIÓN EN KANT
}

Luis Argudín

INSTITUTO dE INVESTIGaciones FiLOSÓficas Universidad Nacional Autónoma de MÉxico

Tanto Kant como Hume manejaron tres distintas nociones de imaginación. La primera se refiere a la imaginación creativa que ejercemos ante los objetos estéticos y cuyo desarrollo extremo caracteriza al genio artístico. A la ficción propia de lo imaginario le adjudicamos aquí un valor estético. Desde un punto de vista lógico, la segunda noción enfatiza el aspecto de irrealidad de lo imaginario, como lo falso e ilusorio, producto de la fantasía. La tercera noción de la imaginación considera que ésta es un ingrediente necesario de la percepción misma, que le da coherencia y colabora con la facultad conceptual a estructurar las apariencias. En este trabajo nuestro interés recaerá únicamente en las versiones uno y tres: la imaginación creativa y la perceptual. El argumento en la "Analítica de lo Bello", de la Critica del Juicio, se centra en la confrontación de estas dos interpretaciones de la función de la imaginación; la primera muestra a la imaginación como un estado de no defiSpontaneitat im Spiele des Erkenntnisvermögen..." (Introducción, Krison los sentidos bajo el título general de imaginación, y la facultad de los conceptos o entendimiento) se relacionan libremente, mientras que la segunda muestra a la imaginación al servicio del entendimiento, proveyendo el material sensible para un juicio cognoscitivo. Para definir la actitud estética, Kant introduce el concepto de juego. Él se refiere a la actitud estética como un estado donde el intelecto y la sensibilidad, el pensamiento y la percepción, entablan una relación de juego: "Die Spontaneitat im Spiele des Erkenntnisvermögen..." (Introducción, Kritik der Urteilskraft, LVII, p. 35, Philosophische Bibliothek.)

El juego entre las facultades describe una relación armónica, no constreñida por leyes, entre la facultad de la imaginación y la facultad de los conceptos. Ésta es la tesis fundamental que sostiene Kant sobre el juicio de gusto y el núcleo de su teorfa estética.

El desarrollo de este trabajo será el siguiente. Una primera sección introduce el concepto kantiano de imaginación, tanto en su aspecto empírico como en su aspecto trascendental. La segunda sección presenta 
el concepto de juego y la interacción estética entre las facultades cognoscitivas, mientras que la tercera y última sección expone una interpretación alejada del texto kantiano pero necesaria para describir el juego en la experiencia estética. El método en las dos primeras secciones será exegético, mientras que en la tercera nos liberaremos de lo propiamente adjudicable a Kant para sugerir ciertas relaciones entre Kant y otros autores, asf como para discutir un tema del que Kant específicamente no se ocupa.

Antes que Kant, ya Hume le habia adjudicado a la imaginación un papel central en la creación de nuestra percepción del mundo. Sin embargo, se había topado con problemas al fundar el sentimiento de lo real en la síntesis de la imaginación, siendo que esta facultad se caracteriza, según Hume, por la creación de lo irreal y lo fantasioso. Según Hume, únicamente podemos estar totalmente seguros de las más sencillas "impresiones" sensoriales, así como de las verdades tautológicas; el resto es creencia basada en la fantasía. El conocimiento del mundo se basa meramente en lo probable, esto es, en la experiencia que parte de la costumbre o inclinación que tiene la mente a completar el cuadro parcial de la experiencia sensible. La razón, incapaz de inferir lo cierto de lo probable, o lo idéntico de lo similar, tiene sólo la función escéptica de dudar de una realidad, cuyo único sustento es un hábito ineludible de la mente. Esta inclinación a rellenar imaginativamente el contenido de la experiencia produce un sentimiento vívido de la realidad, que se distingue del sentimiento que tenemos hacia lo imaginario o irreal, cuantitativa y no cualitativamente. La diferencia entre un hecho real recordado y un hecho imaginado es solamente de grado; el primero es más vívido que el segundo.

La imaginación es, entonces, para Hume, una tendencia de la mente a creer en la existencia continua de objetos independientes de uno, que, sin embargo, es tan falaz como la creencia en supersticiones irracionales. Esto se muestra en múltiples referencias a la imaginación como "...una inclinación a fingir la existencia continua de todos los objetos sensibles..." (Tratado sobre el Entendimiento Humano, Libro I, Parte IV, Sección II; ed. Porrúa, p. 139). "Esta inclinación a conceder la identidad a nuestras percepciones semejantes produce la ficción de una existencia continua, ya que esta ficción, lo mismo que la identidad, es realmente falsa, como se reconoce por los filósofos." (Ibid.) Lo que se muestra aquí es que hay dos principios que se oponen mutuamente. Por un lado, la imaginación produce una creencia en la continuidad de los 
objetos en el tiempo y el espacio, mientras que, por el otro, la reflexión . contradice esta creencia falaz, sosteniendo que lo único de que podemos estar seguros son nuestras impresiones fugaces.

La contradicción entre estas opiniones la eludimos mediante una nueva ficción que concuerda con las hipótesis de la reflexión y la fantasía, atribuyendo estas cualidades contrarias a existencias diferentes: la interrupción a las percepciones y la continuidad a los objetos. (Ibid., p. 142.)

Ahora bien, al haber sido despertado de su sueño dogmático por el escepticismo de Hume, Kant se encuentra ante el problema de cómo fundamentar el conocimiento que tenemos del mundo sobre principios objetivos o, como él los llama, "a priori", pues ni el conocimieno que tenemos del mundo, ni el arte que engrandece y vivifica nuestro espíritu, pueden originarse en una mera "superstición" del alma. Es necesario deslindar lo imaginario de lo real, tanto para sentar sólidas bases para la ciencia, como para entender el fenómeno artístico. En función de ambos fines Kant se ve obligado a postular dos distintas facetas de la imaginación: la empirica o contingente, que es del dominio de la psicología, y la trascendental, producto de su sistema, que establece las "formas" a priori de la experiencia.

La imaginación, en tanto función trascendental de la síntesis que la conciencia hace de su experiencia, obedece a los conceptos puros del entendimiento, o sea a las categorías de cantidad, cualidad, relación y modalidad. Conforme a éstas la imaginación determina a priori la forma de la experiencia, razón por la cual el entendimiento puede conocer el mundo. Pero clarifiquemos esto un poco más. Hume había descubierto tres principios, mediante los cuales las impresiones se combinan para formar la imagen de un objeto: la similitud que una impresión tiene con otra, la contigüidad que se da entre las impresiones y la secuencia de causa y efecto, resultado de la sucesión entre ellas. Estos principios Kant los considera como asociaciones meramente contingentes que pertenecen al aspecto empírico de la imaginación y cuyo estudio se debe dejar a la psicología. El verdadero problema de la imaginación es cómo dar el salto de las impresiones sensoriales a las ideas $u$ objetos determinados por conceptos (Hume trata sobre esto en Treatise on Human Nature, Book I, Part III, Section VI). Según Kant, la relación de similitud, contigüidad o sucesión entre impresiones, por muchas veces que se repita, no nos puede llevar a formar un objeto público, independiente de nuestra percepción. Sólo los conceptos, y no el hábito, pueden juntar coherentemente impresiones múltiples en objetos mediante reglas hechas por el entendimiento. Lo importante, para Kant, por ende, es 
cómo se relacionan los conceptos con sus contenidos empíricos (cómo aplicamos los conceptos al mundo) y cómo, a partir de la múltiple variedad de la experiencia sensible, podemos reconocer un contenido sensorial como la instancia de un concepto (en otras palabras, cómo reconocemos objetos individuales mediante la relación con su concepto).

Tomemos uno de estos casos: el reconocimiento de las formas de un objeto como la instanciación de un concepto. Según Kant, nos es posible reconstruir en las apariencias la configuración de un objeto conocido mediante cierto orden o sistema que encontramos en su aspecto.

La regularidad, que conduce al concepto de un objeto, es ciertamente la condición indispensable (conditio sine qua non) para coger el objeto en una representación única y determinar lo diverso en la forma del mismo. (C. J., ed. Porrúa, p. 235.)

Dependemos de la regularidad y del orden de las formas de la experiencia para poder reconocer $y$, por lo tanto, pensar a lo aparente como un objeto. Hume había notado que sentimos las impresiones en grupos (familias de sense-data, según Price), por lo que el papel de la imaginación no es tanto el de crear el orden de lo percibido, sino el de completar un ordenamiento que de hecho poseen nuestras percepciones. En cambio, para Kant, el papel de la imaginación es trascendental y a priori pues esta regularidad de las formas no es algo dado por la experiencia ("no podemos representarnos nada como enlazado en el objeto sin haberlo enlazado previamente nosotros mismos" (C. R.P., ed. Porrúa, p. 80)), sino que la presupone. La imaginación empírica establece las asociaciones contingentes que ligan, digamos, el sabor de una fruta con el recuerdo de una persona o de una vivencia. La imaginación trascendental, en cambio, conforma la experiencia de manera necesaria, a priori, con las formas básicas y la regularidad sin las cuales sería ininteligible el contenido sensorial. Según Hume, de hecho el mundo muestra un cierto ordenamiento; para Kant, éste es el orden que la imaginación trascendental proyecta de manera que el material de los sentidos tenga la unidad necesaria para ser objeto del entendimiento y, por lo tanto, cognoscible.

En el segundo caso de la relación entre la imaginación trascendental y la experiencia, Kant se pregunta cómo es posible que un concepto, que es una serie de reglas abstractas del entendimiento, se aplique al contenido de la experiencia. Para él, como para Hume, todo concepto es un agregado de experiencias, pero este contenido empírico de un concepto no nos da las reglas para la aplicación del concepto a la experiencia. Si pensamos en el concepto "línea", trazamos mentalmente una 
línea, creándonos una imagen de ella. Pero esta imagen no puede expli. car cómo aplicamos el concepto al objeto denotado, porque su contenido (la imagen que nos hacemos) es específico. Al pensar en una línea, podemos concebir líneas curvas, rectas, quebradas, etc., por lo cual, la imagen no puede cubrir la generalidad de los casos encontrados de hecho. Para poderlo aplicar necesitamos de una regla o procedimiento abstracto que, sin ser derivado de la experiencia, determine la aplicación del concepto cuando sea necesario. Esta regla, dada por la imaginación trascendental, conforme a las categorías del entendimiento, es el esquema de un concepto. El esquema es un procedimiento general de síntesis, por el cual la imaginación establece un cierto territorio de aplicación para un concepto. El esquematismo del entendimiento, junto con la regularidad en las formas que posibilita el reconocimiento de lo aparente como la instancia de un concepto, agotan la función trascendental de la imaginación, que presupone la experiencia de un mundo coherente de objetos provistos de una continuidad en el tiempo y el espacio.

Hasta aquí hemos visto la facultad de imaginar en su función ordenadora de la experiencia, no como un proceso que elabora impresiones sensoriales básicas en conjuntos más complejos o imágenes, como pensaba Hume, sino como la síntesis a priori que presupone la experiencia de un mundo coherente de objetos independientes del que percibe. Para que nuestra experiencia sea tal, y estemos conscientes de un objeto mental o perceptual, el contenido de nuestra experiencia debe llevar implícita ya una síntesis o interpretación por parte de la imaginación, interpretación que se da a priori, de acuerdo con los conceptos puros del entendimiento. Como en el caso de las ilusiones ópticas, puede haber varias interpretaciones, pero sin una síntesis interpretativa no hay experiencia.

\section{II}

En la sección 54 de la Critica del Juicio, Kant distingue entre tres distintos tipos de juego:

Podemos dividir esos juegos en el juego de azar (Gluckspiel], el juego tonal (Tonspiel) y el juego de ingenio (Gedankenspiel). El primero solicita un interés (ya sea ganar o perder), el segundo exige sólo el cambio de las sensaciones...; el tercero nace sólo del cambio de representaciones en el Juicio, mediante las cuales no se produce pensamiento alguno que lleve consigo algún interés, pero el espíritu es, sin embargo, vivificado. (C.J., ed. Porrúa y ed. Andrés Bello, Chile, 1983.) 
En los juegos de azar o de suerte, la atención se centra en el placer que nos causa aquello que favorece nuestros intereses, contrastado con el dolor o disgusto que suscita lo que los contraría. Así, mantenemos nuestro interés en el juego mediante un sistema de convenciones que nos premia o nos castiga según la circunstancia.

En lo que llama juegos de "ingenio" Kant se refiere a una tradición cultivada por la estética inglesa -que usaba la analogía del ingenio o "wit"- para contrastarla con el juicio del intelecto. ${ }^{1}$ De esta manera, si el intelecto distingue en lo similar la diferencia que hay con lo idéntico, el ingenio encuentra similitud entre lo aparentemente inconexo. La definición que Kant da de las ideas estéticas está, en parte, basada en el concepto inglés de "wit" (como podemos ver en la cita de Locke, en la nota 1):

...entiendo por idea estética la representación de la imaginación que provoca a pensar mucho, sin que, sin embargo, pueda serle adecuado pensamiento alguno, es decir, concepto alguno, y que, por lo tanto, ningún lenguaje expresa del todo ni puede hacer comprensible. (C. J., ed. Porrúa, p. 283.)

El comentario ingenioso rompe el hilo normal de la plática trayendo a colación una idea que, aunque aparentemente no esté relacionada con lo discutido, nos muestra, desde un ángulo distinto, el tema tratado. Esta diferencia de perspectiva la da el humor, bajo cuya égida solemos considerar el mundo en formas, no sólo distintas, sino a veces diametralmente opuestas a lo usual. Esta ruptura de lo habitual nos produce una cierta sensación exhilarante que se canaliza mediante la risa:

1 Joseph Addison, en sus ensayos del Spectator (Clarendon Press, 1970) utiliza una cita de Locke para distinguir entre ingenio y juicio: "For wit lying most in the assemblage of ideas, and putting those together with quickness and variety, wherein can be found any resemblance or congruity, thereby to make pleasent pictures and agreeable visions in the fancy: Judgement, on the contrary, lies quite on the other side, in separating carefully, one from the another, ideas wherein can be found the least difference, thereby to avoid being misled by similitude, and by affinity to take one thing for another. This is a way of proceeding quite contrary to metaphor and allusion, wherein for the most part lies that entertainment and pleasentry of wit which strikes so lively on the fancy" (en Locke: Bk. II, Ch. XI, Essay Concerning Human Understanding). Addison apunta que, para que un comentario sea ingenioso, la comparación o relación entre una y otra idea debe ser novedosa. Comparar el pecho de la amada con la blancura de la nieve es demasiado obvio, pero agregar que también es tan frío como la nieve ya implica ingenio, y esto nos place. El verdadero ingenio, que consiste en el parecido entre las ideas y no en el parecido de las palabras, usa conceptos con fines expresivos y no descriptivos. Implica la juguetona dislocación del hilo de nuestras ideas. A las ideas expresivas, y no descriptivas, Kant las llama estéticas. 
La risa es un afecto debido a la transformación repentina de una tensa espera en nada. Precisamente esta transformación, que ciertamente no es halagüieña para el entendimiento, alegra, empero, indirectamente, por un instante, de muy vívida manera. (C.J., ed. Andrés Bello, Chile, 1983, p. 292.)

Tântô eñ los juegos de azar couno en los del ingenio, el interés surge de un sentimiento gratificante $y$, por lo tanto, corporal. En los primeros porque se juega con sentimientos de placer y dolor, mientras que en los segundos, porque Kant piensa que el humor y la risa son el resultado de oscilaciones, tensiones y relajamientos corporales que, aunque tengan su origen en ideas estéticas, éstas causan un efecto simpático en el cuerpo, que desemboca en una descarga física: la risa. En los juegos "tonales" o musicales, Kant sostiene que los sonidos afectan nuestras sensaciones directamente y que, aun cuando estas sensaciones causen ideas estéticas, finalmente se fundan en una gratificación física. Kant está muy alejado del sentimiento de reverencia de Schopenhauer hacia la música, ya que, al ser el medio artístico más inmediato, es para el primero el más sensorial, mientras que para el segundo es el más libre, pues, por su misma inmediatez, está más alejado de la voluntad del yo. ${ }^{2}$

El inconveniente que Kant encuentra en los tres tipos de juego, desde el punto de vista estético, es que al fundarse en lo gratificante carecen de la dimensión moral y de la libertad que resulta de la oposición lúdica entre facultades. Distingue así entre dos clases de juego: el juego de las sensaciones (donde lo importante es el cambio de una sensación a otra), y el juego armónico entre diferentes facultades. ${ }^{3}$ En el primer sentido, la palabra juego significa el flujo continuo de la imaginación,

2 Con Tonspiel Kant no se refiere a la música, en verdad, en cuanto arte, sino a la actitud que tenemos cuando ofmos música ligera sin prestarle atención; la mú. sica de fondo de una fiesta. En cambio, cuando escuchamos música seria no nos dejamos ir en el flujo de nuestras cambiantes sensaciones, sino que buscamos el sentido y la forma de la música. La imaginación traba relación con el entendimiento. Otro ejemplo de Tonspiel podría ser el cine; como apunta Walter Benjamin (Iluminaciones), en la sucesión constante de imágenes no se nos permite distanciarnos para contemplar cada una de las imágenes; se nos arrastra, por el contrario, al ritmo de un movimiento que es psicológicamente irresistible, pues, Kant diría, reproduce el flujo de la imaginación, al cual se había referido con el ejemplo del fuego y del arroyo. Puede haber aquí una explicación de tono kantiano de la dificultad que ha encontrado el cine para ser considerado una forma seria de arte, ya que su naturaleza se acomoda tan bien al agradable juego de las sensaciones, que divierte pero que no place estéticamente.

3 Basándose en Kant, Schiller distingue entre "Juego físico" y "Juego estético", en forma análoga a como Kant diferencia entre el placer en lo agradable, que nos gratifica, porque estimula nuestras pasiones e intereses $-y$ es en última instancia subjetivo-, y el placer en lo bello, que nos place porque es en alguna manera reflexivo -y por ello, válido intersubjetivamente (C.J., 3). 
donde las imágenes se suceden unas a otras manteniendo.a la mente en actividad constante. Ésta es la respuesta:

...cuando se miran las figuras cambiantes de un fuego de chimenea o de un arroyo que corre, los cuales sin ser ninguno de las dos bellezas, llevan consigo, sin embargo, un encanto para la imaginación, porque mantienen su libre juego. (C.J., ed. Porrúa, p. 236.)

$\mathrm{Ni}$ el arroyo ni el fuego son objetos de un juicio estético, porque al poner en movimiento nuestras sensaciones no relacionan a la imaginación con el entendimiento, esto es, nos dejamos llevar por el flujo de las asociaciones libres de la fantasía sin hallar una concordancia con el entendimiento. El juego estético de las facultades, por el contrario, ya no es la mera sucesión de sensaciones agradables, que nacen de una necesidad física y se extinguen con su satisfacción. Tampoco es el placer que surge de la pura continuidad de las sensaciones, las cuales mantienen a la mente entretenida en el flujo de su propio movimiento psicológico. El Juego que se da en el juicio estético relaciona armónicamente la facultad de imaginar con la facultad de los conceptos o entendimiento. Veamos qué significa esto.

En nuestra percepción normal del mundo subsumimos la múltiple variedad del contenido sensorial bajo esquemas de la imaginación en concordancia con el entendimiento. Así, la apariencia de algo con cuatro extremidades, cola y demás características, sintetizada por un esquema, concuerda con el concepto de perro, gracias al cual reconocemos en la apariencia al fiel animal. Aquí el contenido sensorial es clasificado bajo el concepto general "perro", lo que da, según Kant, un juicio cognoscitivo. ¿Qué pasa ante un juicio estético, en oposición a este ejemplo? En el juicio estético el contenido sensorial no puede ser determinado por un concepto $y$, sin embargo, debe haber una concordancia con el entendimiento, puesto que sentimos que hay un propósito en las formas del objeto bello. Por lo tanto, la síntesis sensorial de la imaginación debe armonizar con los fines cognoscitivos del entendimiento.

Es decir, como la libertad de la imaginación consiste precisamente en que esquematiza sin concepto, debe el juicio de gusto descansar en una mera sensación de la mutua animación de la imaginación en su libertad, y del entendimiento, con su conformidad con leyes; descansar, pues, en un sentimiento que permita juzgar el objeto según la finalidad de la representación (mediante la cual un objeto es dado) para la impulsión de las facultades de conocer en su libre juego, y el gusto, como juicio subjetivo, encierra un principio de subsunción( no de las intuiciones bajo conceptos, sino de 
la facultad de las intuiciones (es decir, la' imaginación) bajo la facultad de los conceptos (es decir, el entendimiento), en cuanto la primera, en su libertad, concuerda con la segunda en su conformidad da leyes. (C. J., ed. Porrúa, p. 266.)

Esta armonía entre entendimiento e imaginación es posible porque, como ya hemos visto, la imaginación no es únicamente reproductiva (totalmente regida por las leyes psicológicas de la asociación), sino también productiva (ya que activamente determina la forma a priori de nuestra percepción). El ejemplo de esto es el esquematismo, donde la imaginación, bajo las reglas del entendimiento, produce un esquema de un concepto dado. Ahora bien, en el juicio de gusto Kant sostiene que la imaginación produce un esquema sin que un concepto la determine. En este caso el esquema obedece a un sentimiento de que hay un propósito, sin por ello haber un concepto. De esta forma, la imaginación, por sí misma, nos da aquello (la finalidad) que la tarea del entendimiento debe proveer.

La feliz reunión de imaginación y entendimiento se da bajo dos requisitos: 1) cuando el objeto mismo ofrece a nuestra percepción tales formas como las que produciría la imaginación, de acuerdo con sus propias leyes, y 2) cuando el entendimiento no nos impone un concepto o regia bajo la cual ordenar el contenido perceptual (en la Nota General a la primera sección de la "Analítica de lo Bello").4

Según Kant, llamamos a un objeto bello cuando sus formas se ajustan al movimiento libre de la imaginación. Las formas rígidamente regulares no permiten el juego de las facultades, porque traslucen un propósito determinado, esto es, sus formas son propicias a la comprensión y no a la contemplación. En la sección 16 de la "Analítica de lo Bello", Kant llama bellezas puras a las formas libres, los arabescos, los garabatos y los diseños ornamentales que no representan ningún objeto porque carecen de una finalidad conceptual (con lo cual cumplen el punto 2), por lo que no pueden ser asimilados por el entendimiento y, en consecuencia, exigen la contemplación detenida de sus formas. La belleza, sin embargo, es aquella forma que, sin perder el interés de la imaginación (pues la riqueza de su trazo mantiene nuestra atención), muestra un fin o propósito en sus formas. En oposición a las figuras geométricas simples, la forma bella presenta una unidad dentro de su variedad que, al darle un carácter problemático a su estructura, la emparenta con los fines cognoscitivos del entendimiento. Lo bello nos causa placer no sólo por el juego entre las facultades, al concordar libremente la imaginación con los fines del entendimiento; también nos causa placer el

4 El tema es tratado en Guyer, Kant and the Claims of Taste, Cap. 3. 
reto intelectual que implica descubrir sentido en las formas de lo bello; placer que Kant ha descrito como placer en lo bueno (Wohlgefallen am Guten) y que puede ser interpretado como el placer que sentimos ante la buena factura de un artefacto, placer en el control del material y en la maestría de la ejecución, así como en la solución de un problema. El problema, desde el punto de vista estético, con las figuras regulares geométricas, no es que sean inteligibles, sino que lo son en demasía. Si desde Platón el círculo, el cuadrado y el triángulo habían sido considerados como paradigmas de lo bello, para Kant estas figuras son paradigmas de la perfección, que remite al entendimiento y a sus conceptos, y no al gusto. Pero al rechazarlos como el modelo ideal de lo bello, Kant no busca expulsar ni separar al placer intelectual del estético; más aún: "Ciertamente, mediante ese enlace de la satisfacción estética con la intelectual gana el juicio de gusto..." (C. J., 16, Porrúa, p. 277). En la concordancia de estos dos tipos de placer encontramos la reunión lúdica de la imaginación y el entendimiento en el juicio de gusto, sin que sea regido por conceptos o dominado por las sensaciones.

Una última consideración sobre la relación de las facultades como juego nos revela que el descubrir sentido en las formas de lo bello no se da en un instante especffico e irrepetible en el tiempo. Al usar el término Spiel, juego, Kant nos da a entender que el descubrir sentido estético es un proceso que se extiende en el tiempo, contrariamente al acto de reconocer una sombra en la oscuridad como la silueta de un árbol. Cuando en lo aparente reconocemos un objeto, este reconocimiento es final y definitivo; al saber que la silueta es un árbol, difícilmente podemos mantener el estado de no definición en que proyectábamos hipótesis interpretativas a la forma. En la contemplación estética, por el contrario, el proceso de encontrar finalidad en las 'formas se continúa en el tiempo; jugamos con distintas interpretaciones y descubrimos cada vez más maneras de combinar o hacer sentido de las formas. El juego de las facultades cognoscitivas revela que, para Kant, la reflexión estética es un proceso rico e interminable que se prolonga en el tiempo y que se puede interrumpir o retomar a placer del sujeto.

\section{III}

En la primera sección hemos visto el concepto kantiano de la imaginación, y en la segunda, el del juego entre esta facultad y el entendimiento. En esta tercera sección quiero tratar el tema de la ambigüedad con relación al juego, tema que Kant no menciona especificamente, pero que considero importante para la comprensión de la experiencia estética. 
Como ya dijimos en la introducción, ésta tercera sección, aunque formulada en términos kantianos, no pretende ser una exégesis de Kant sino desarrollar ciertas ideas sugeridas en el texto.

Para comenzar quisiera introducir dos términos usados por R. Scruton en The Aesthetics of Architecture, pensando en las dos funciones primordiales que tiene la imaginación en Kant; la imaginación, en tanto parte esencial de la síntesis de la percepción, participa en lo que Scruton llama la "percepción literal", la cual contrasta con la función imaginativa que adjudicamos a las actividades artísticas y que él llama la "imaginación creativa". Ahora bien, se puede decir que Kant sostiene que existe una continuidad entre la percepción literal y la imaginación creativa, pues en ambos casos la mente interpreta la organización de su objeto de atención. Siendo éste el común denominador, la diferencia se limita a que, en la primera, lo que determina la interpretación es un concepto, mientras que en la segunda no hay concepto que la rija. Con respecto a la percepción literal, el criterio que guía la actividad de la imaginación es determinado por el entendimiento. De manera que lo prioritario es la fijación del sentido de los conceptos. Nuestro percibir busca activamente la clasificación del contenido sensorial bajo un concepto, esto es, el reconocimiento de lo aparente como la ejemplificación del contenido de un concepto. Este percibir es literal, porque su fin es llegar a una conclusión definitiva —el reconocimiento del objeto- que nos permita pasar de la interpretación perceptual a la acción. Aquí, por lo tanto, el enemigo es la ambigüedad, pues nos obstaculiza el pronto reconocimiento del objeto y, al hacernos dudar, cuestiona la realidad de su existencia. A esta literalidad de la percepción se refería Hume al ligar el sentimiento de realidad que tenemos de los objetos en el mundo con el hábito. La duda y la reflexión rompen el procedimiento habitual de interpretación de la visión y, al hacerlo, cuestionan la realidad de los objetos percibidos.

Pero en el caso de la imaginación creativa, el criterio que rige la actividad de la imaginación ya no es la fijación conceptual del sentido de nuestra percepción, sino la libre continuidad del flujo de la imaginación. Para lograr esto y a la vez evitar que la experiencia se fije en un sentido específico, es necesario explotar al máximo la ambigüedad de lo perceptible. Cuando se da esta ambigüedad y la fijación del sentido de lo percibido no se logra, la imaginación, en su capacidad interpretativa, se verá libre de buscar otras maneras de proyectar sentido. Sobre esto, veamos lo que dice Rudolf Arnheim, psicólogo de la escuela de la Gestalt: 
Otros estudios pusieron de manifiesto que si se debilita la influencia del estímulo mediante una iluminación escasa, una exposición corta, distancia temporal, etcétera, el aparato receptor goza de libertad para ejercer un influjo formativo sobre el percepto. ("La abstracción perceptual y el arte", en Hacia una psicologia del arte, Alianza Forma, Madrid, 1980, p. 40.)

En estos casos, donde la carencia de suficiente información perceptual rompe la literalidad de la visión, encontramos una semejanza con la actitud creativa y lúdica, con la cual percibimos los objetos de arte. Al no poder fijarse el sentido, nuestra visión prueba distintas hipótesis visuales mediante las cuales sea posible estructurar lo aparente. Hasta que no lo logre en la ambigüedad existente, la percepción literal y la imaginación creativa se verán identificadas.

Esta irresolución, sin embargo, no es en general prolongada, pues el intelecto rápidamente busca confirmar su interpretación para adjudicarle realidad a lo aparente. Lo que resalta aqui es que la diferencia esencial, el sine qua non de la imaginación creativa, no es tanto la ambigüedad en la apariencia del objeto, sino el hecho de que esta ambigüedad perceptual pueda causar una ambigüedad similar en nuestros fines o propósitos, o en otras palabras, que estimule una actitud lúdica que rompa la habitual percepción literal: en lenguaje kantiano, que se dé una actitud perceptual cuyo único propósito sea la continuidad de su propio estado. Lo importante es que haya un cambio de actitud, el cual, según Kant, es determinado por el "desinterés" y, según Edward Bullough, por el "distanciamiento psíquico". El que veamos un objeto difusamente, ya sea porque esté lejos, ya sea porque haya bruma o poca luz, no determina que se dé una actitud desinteresada. Al contrario, al ver una sombra en la obscuridad buscamos con mayor ahínco su posible configuración de hombre, animal u objeto. Lo que hace este "debilitamiento de la influencia del estímulo" es activar la imaginación a tal punto que su funcionamiento se vuelve autónomo. Ésta es una de las principales características de la imaginación creativa, como vimos en el ejemplo que da Kant sobre la contemplación del fuego o de un arroyo, aunque no el factor que la distingue. Esencial a la imaginación creativa es el "desinterés" o "distanciamiento" (los uso indistintamente), pues cumple, según Bullough, dos requisitos:

Tiene un aspecto negativo, inhibitorio - recortando las facetas prácticas de las cosas y de nuestra actitud práctica hacia ellas- y un aspecto positivo _la elaboración de la experiencia sobre la nueva base creada por la acción inhibitoria de la distancia. (E. Bullough, Aesthetics, Stanford U. Press, 1957, p. 95; traducción mía.) 
La falta de resolución en la apariencia del objeto estimula el aspecto positivo al que se refiere Bullough e, indirectamente, el aspecto negativo de inhibir los fines prácticos que estructuran la realidad de los objetos. La belleza libre de una configuración evita que reconozcamos a qué clase de objetos pertenece y obstruye el juicio cognoscitivo, liberando el juego de la imaginación. El arabesco, los diseños en un papel tapiz, las formas de una flor, al ser desconocidos e inesperados en su configuración específica, exigen un cierto distanciamiento (el distanciamiento aquí es de tipo conceptual: el que se da entre lo familiar y lo desconocido) porque sus formas escapan a la fácil conceptuación que habitualmente llevamos a cabo con los objetos cotidianos. Por eso tenemos que seguir la trama de su apariencia formal para descubrir su estructura y naturaleza. Pero las bellezas libres logran sólo una momentánea liberación de los propósitos cognoscitivos ya que la mente siempre encuentra una hipótesis visual o auditiva, si no justificada, por lo menos plausible. Estos objetos y diseños no son objetos bellos en sí mismos, ya que, teniendo la cualidad de estimular la proyección de interpretaciones perceptuales de la imaginación, no poseen la capacidad de inhibir nuestros propósitos teórico-prácticos más que indirectamente.

Sin embargo, esta capacidad de inhibir nuestra visión práctica o literal hacia el mundo no puede depender totalmente de las características físicas de los objetos ya que, si estos determinaran unilateralmente nuestra actitud, lo sentiríamos como una imposición. Sólo dentro de las convenciones establecidas socialmente para una actividad (en este caso el arte occidental) se puede dar la pauta para la actitud apropiada. Los objetos artísticos estimulan una respuesta distanciada, porque se presentan fuera del círculo de las situaciones reales. Son artefactos que niegan su condición de instrumentos hechos para un fin específico; por eso Kant escribe:

Así pues, la finalidad en el producto del arte bello, aunque es intencionada, no debe parecer intencionada, el arte bello debe ser considerado como naturaleza, por más que se tenga conciencia de que es arte. (C. J. 45, Porrúa, p. 278.)

E inversamente, al considerar a la naturaleza como bella nos interesa lo opuesto:

. . la admiración de la naturaleza, que se muestra en sus productos bellos como arte, no de un modo meramente casual, sino, por decirlo así, intencionadamente, (C. J., 42, p. 275.)

Si ante el arte nos atrae la naturalidad y, ante la naturaleza, la cohe- 
rencia casi intencionada de sus formas, es porque el desinterés estético recorta al objeto bello de su contexto. En palabras de Schiller, crea su ámbito de "apariencia" o ficción (Schein), ajeno a las presiones mundanas que requieren respuestas efectivas. Las convenciones artísticas explotan factores de ambigüedad inadmisibles para la percepción literal, mientras que ésta requiere respuestas definitivas, que serían incorrectas en la ficción artística. 